\title{
Association of Graves' Disease and Hashimoto's Thyroiditis with Insulin-dependent Diabetes Mellitus
}

\author{
Mitsuo Inada and Mitsushige Nishikawa \\ 2 nd Department of Internal Medicine, Kansai Medical University, \\ Moriguchi, Osaka, Japan
}

\begin{abstract}
Seven patients $(2.6 \%)$ with insulin-dependent diabetes mellitus (IDDM) were found in 270 patients with Graves' disease. These patients were all women and the age of onset of IDDM was 30 years of age or later in 5 of 7 patients. The high titers of the antimicrosomal antibody of circulating thyroid antibodies were found in 5 patients. The family history of diabetes mellitus was seen in 4 of 7 patients. Histological examination of thyroid biopsy specimens obtained in 3 of 7 patients disclosed the coexistence of histological abnormalities characteristic of Hashimoto's thyroiditis and the proliferative changes of epithelial cells characterizing Graves' disease, suggesting the histological feature of the thyroid in Graves' disease associated with IDDM.
\end{abstract}

\section{Introduction}

The coexistence of Graves' disease, which is regarded as an autoimmune disease, and insulindependent diabetes mellitus (IDDM) has been noted and the characteristics of these patients have been studied by several investigators ${ }^{1-4}$. They found a significantly higher prevalence of Graves' disease in IDDM, associated with persistence of islet-cell antibodies ${ }^{1-4)}$. These findings suggest that autoimmunity may play an etiologically important role in some cases of IDDM ${ }^{1-4}$ ).

In the present study, 7 patients with IDDM were found in 270 patients with Graves' disease. Histological examination of the thyroid biopsy specimens obtained in 3 of 7 cases revealed the coexistence of the findings of hyperthyroidism associated with Hashimoto's thyroiditis.

\section{Patients and Methods}

Seven patients $(2.6 \%)$ with IDDM were found in 270 patients with Graves' disease, who were examined in the out-patient clinic of the hospital. The diagnosis of Graves' disease was established on the basis of clinical pictures and determinations of serum $T_{4}$ and $T_{3}$ concentrations and thyroid ${ }^{131} \mathrm{I}$ uptake. Diabetes mellitus was diagnosed by the results of blood sugar and immunoreactive insulin (IRI) responses to $50 \mathrm{~g}$ oral glucose loading as well as by clinical 
symptoms such as thirst, polydipsia and polyuria.

Plasma IRI level was determined by RIA using double antibody technique. Serum $\mathrm{T}_{\mathbf{4}}$ and $\mathrm{T}_{3}$ were determined by RIA. $T_{4}$ values in normal subjects ranged from 5 to $13 \mu \mathrm{g} / 100 \mathrm{ml}$ and $\mathrm{T}_{3}$ values from 85 to $180 \mathrm{ng} / 100 \mathrm{ml}$. Intraassay and interassay variations in IRI, $\mathrm{T}_{4}$ and $\mathrm{T}_{3}$ determinations were under $11 \%, 7 \%$ and $7 \%$, respectively. Thyroid antibodies in serum were examined by the thyroglobulin-coated and microsome-coated tanned red blood cell hemagglutination tests. An antibody titer over 1:100 was considered to be abnormal in these tests. No substantial differences in the antibody titers were found either within an assay or between assays. Twenty-four-hour thyroidal uptake of ${ }^{131} \mathrm{I}$ was measured by the standard technique, and the normal values in our laboratory were 7 to $35 \%$. Silverman biopsy needle was used for percutaneous needle biopsy of the thyroid ${ }^{5)}$ The obtained specimen, about $0.1 \times 1 \mathrm{~cm}$, was fixed by $6 \%$ formalin's solution, and stained with hematoxylin and eosin.

\section{Results}

As shown inTable 1, 7 insulin-dependent diabetics associated with Graves' disease were all women, whose ages ranged from 22 to 71 years (Table 1). The age of onset of diabetes was

Table 1 Summary of results obtained in thyroid function tests and glucose tolerance test

\begin{tabular}{|c|c|c|c|c|c|c|c|c|c|c|c|c|c|c|c|}
\hline \multirow{3}{*}{$\begin{array}{c}\text { No. of } \\
\text { Case } \\
1\end{array}$} & \multirow{3}{*}{$\begin{array}{l}\text { Name } \\
\text { KT }\end{array}$} & \multirow{2}{*}{ Sex } & \multirow{2}{*}{ Age } & \multirow{2}{*}{$\begin{array}{l}\text { Family } \\
\text { history } \\
\text { of DM }\end{array}$} & \multirow{2}{*}{$\begin{array}{l}131_{\text {I thyroid }} \\
\text { uptake }(\%)\end{array}$} & \multirow{2}{*}{$\frac{T_{4}}{(\mu \mathrm{g} / 100 \mathrm{ml})}$} & \multirow{2}{*}{$\begin{array}{c}\mathrm{T}_{3} \\
\text { (ng/100 ml) }\end{array}$} & \multirow{2}{*}{$\begin{array}{l}\text { Thyroid } \\
\text { test }\end{array}$} & \multirow{2}{*}{$\begin{array}{l}\text { Microsome } \\
\text { test }\end{array}$} & \multicolumn{6}{|c|}{$50 \mathrm{~g}$ OGTT (gluoose $\mathrm{mg} / 100 \mathrm{ml} / \mathrm{IRI} \mu \mathrm{U} / \mathrm{ml}$ ) } \\
\hline & & & & & & & & & & before & $30 \mathrm{~min}$ & 60 & 90 & 120 & 180 \\
\hline & & $\mathbf{F}$ & 22 & + & 72 & 18.2 & 520 & - & $\times 10^{4}$ & $207 / 10$ & $308 / 6$ & $458 / 8$ & $395 / 7$ & $385 / 8$ & $265 / 9$ \\
\hline 2 & KU & $\mathbf{F}$ & 32 & + & 63 & 21.6 & 390 & - & - & $308 / 11$ & $398 / 14$ & $424 / 22$ & $454 / 12$ & $445 / 11$ & $362 / 8$ \\
\hline 3 & ST & $\mathbf{F}$ & 45 & - & 62 & 22.5 & 365 & - & $\times 10^{3}$ & $296 / 16$ & $443 / 18$ & $574 / 9$ & $.544 / 15$ & $443 / 19$ & $329 / 17$ \\
\hline 4 & HM & $F$ & 46 & - & 57 & 21.8 & 343 & $\times 10^{4}$ & $\times 10^{6}$ & $170 / 17$ & $312 / 17$ & $340 / 27$ & $276 / 38$ & $236 / 22$ & $173 / 29$ \\
\hline 5 & SM & $\mathbf{F}$ & 48 & + & 54 & 21.3 & 410 & $\times 10^{3}$ & $\times 10^{5}$ & $171 / 5$ & $273 / 4$ & $378 / 7$ & $367 / 6$ & $340 / 6$ & $261 / 6$ \\
\hline 6 & UM & $\mathbf{F}$ & 70 & - & 63 & 17.9 & 260 & $\times 10^{2}$ & - & $146^{*}$ & $232 *$ & $264^{*}$ & $317^{*}$ & $386^{*}$ & $351^{*}$ \\
\hline 7 & MM & $\mathbf{F}$ & 71 & + & 50 & 17.4 & - & $\times 10^{4}$ & $\times 10^{6}$ & $132 / 18$ & $291 / 101$ & $342 / 94$ & $276 / 86$ & $206 / 54$ & $114 / 47^{* *}$ \\
\hline & & & & & & & & & & $203 / 6$ & $300 / 7$ & $395 / 7$ & $430 / 15$ & $360 / 7$ & $270^{\prime} 5^{* * *}$ \\
\hline Norma & al range & & & & $7-35$ & $5-13$ & $85-180$ & & & & & & & & \\
\hline
\end{tabular}

OGTT, oral glucose tolerance test; IRI, immunoreactive insulin

* IRI was not determined because glucose tolerance test was performed after

insulin therapy

** The first glucose tolerance test

*** Glucose tolerance test was repeated about 10 months after the first test

20 years of age or below in 2 cases and 30 years of age or later in the remaining 5 cases. Four patients had family history of diabetes and a patient had that of thyroid disease (Table 1). All patients had typical symptoms of thyrotoxicosis with diffuse goiters and had elevated serum $T_{4}$ and $T_{3}$ levels as well as elevated thyroid uptake of ${ }^{131}$ I (Table 1). In 3 patients both the antithyroglobulin antibody and the antimicrosomal antibody of circulating thyroid antibodies were positive and the titers of the antimicrosomal antibody were over $1: 10^{5}$ (Table 
1). In other 2 patients the antimicrosomal antibody was positive $\left(1: 10^{3}\right.$ and $\left.1: 10^{4}\right)$, while the antithyroglobulin antibody was undetectable. A patient had only the antithyroglobulin antibody $\left(1: 10^{2}\right)$ and the remaining one patient had no detectable thyroid antibodies in serum

(Table 1). All patients were treated with antithyroid drugs and became clinically euthyroid with normal serum $\mathrm{T}_{4}$ and $\mathrm{T}_{3}$ levels within approximately 2 months after the beginning of the treatment. In spite of the euthyroid state, they had thirst, polydipsia, polyuria and weight loss, associated with glycosuria and elevated fasting blood sugar levels. Their oral glucose tolerance curves were frankly diabetic with low or no responses of IRI (Table 1) and they required insulin therapy for the control of diabetes. No patients had proteinuria and diabetic retinopathy was not found in 6 patients examined. Special attention was paid to 3 patients (K. T., H. M. and M.M.), in whom percutaneous needle biopsy of the thyroid was performed.

Case 1 (K. T. ) - A 22-yr-old woman came to the hospital because of weight loss. About 2 years prior to the onset of weight loss, she began to note palpitation, thirst, polydipsia and polyuria. Her grand father had diabetes millitus. She had a resting pulse of 120 beats $/ \mathrm{min}$., warm and moist skin, finger tremor and a diffuse goiter estimated to be approximately twice normal size. The eyes were normal. Histological examination of the thyroid biopsy specimen obtained before the treatment for Graves' disease revealed parenchymatous hypertrophy suggestive of hyperfunction of the thyroid. In addition, considerable interfollicular lymphocytic infiltration, poorly preserved follicles, degeneration of the epithelial cells and fibrosis were found.

Case 4 (H. M. ) - A 46-yr-old woman came to the hospital because of palpitation and thirst. Her two cousins had goiters. She had history of glucosuria of about 10 years and began to note weight loss about 5 years before. On physical examination, warm and moist skin, finger tremor, and a diffuse goiter estimated to be almost 3 times normal size were noted. Exophthalmos of class 1 (6) was present. The thyroid biopsy specimen obtained before the treatment with antithyroid drug showed papillary infolding of tall epithelium. Moreover, oxyphilic epithelium, interfollicular lymphocytic infiltration and mild fibrosis were observed

Case 7 (M. M. ) - - A 72-yr-old woman came to the hospital because of a diffuse goiter. Her brother had diabetes mellitus. She was clinically hyperthyroid with $\mathrm{T}_{4}$ value of $17.4 \mu \mathrm{g} / 100$ ml. Exophthalmos was not present. Fasting blood sugar levels were either within normal limit or slightly elevated and no glycosuria was found. Although oral glucose tolerance test was diabetic, the basal IRI level of $18 \mu \mathrm{U} / \mathrm{ml}$ was elevated to $101 \mu \mathrm{U} / \mathrm{ml} 30 \mathrm{~min}$ after $50 \mathrm{~g}$ glucose administration (Table 1). Fasting blood sugar levels became completely normal, when thyrotoxicosis was corrected by antithyroid drug therapy. These findings suggest that her glucose intolerance was secondary to thyrotoxicosis. About 4 months after the beginning of the treatment, she became clinically hypothyroid with diminished serum $\mathrm{T}_{4}$ value $(3.2 \mu \mathrm{g} / 100 \mathrm{ml})$ and 


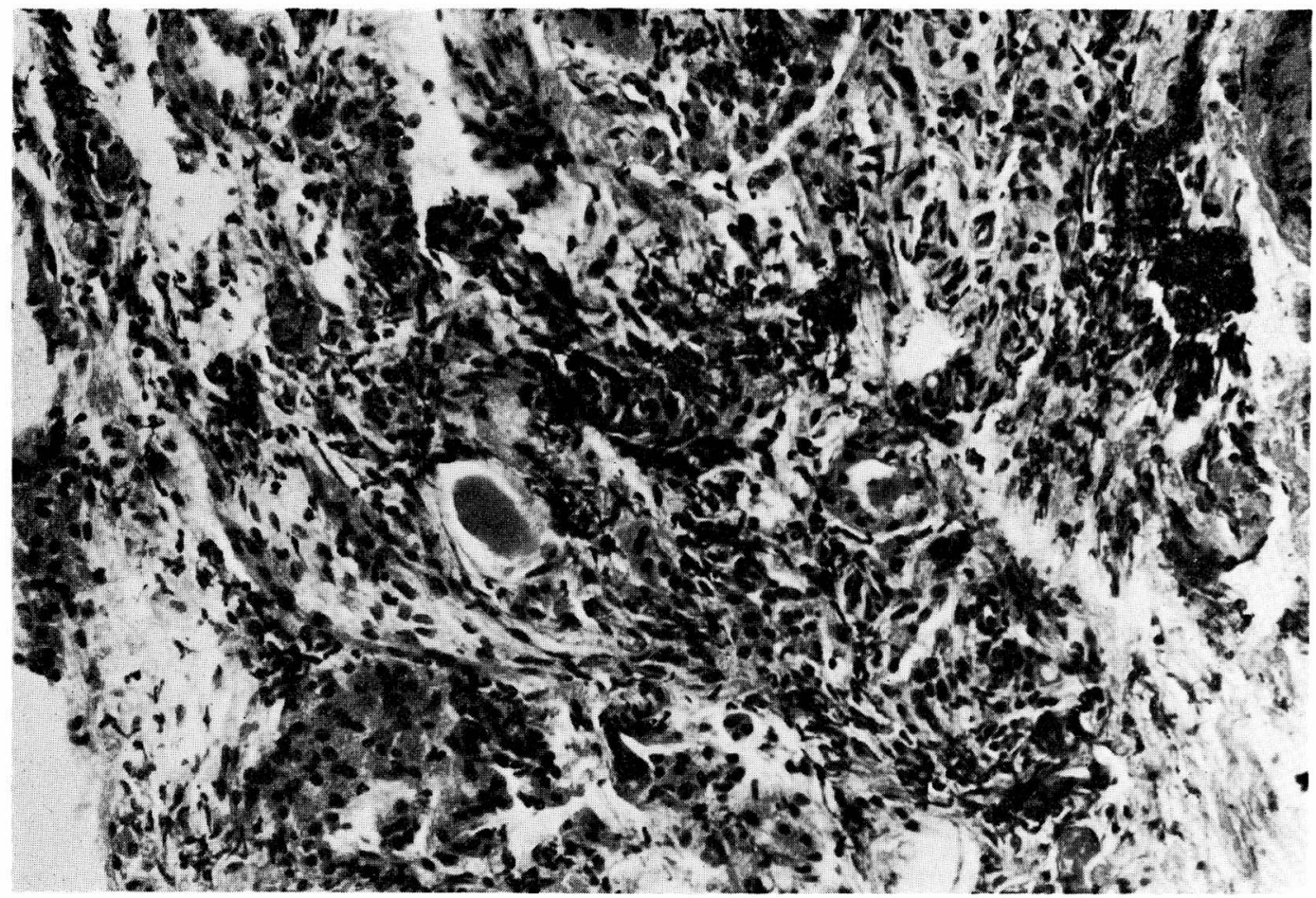

Fig. 1 A Thyroid biopsy specimen of case 7 revealing lymphocytic infiltration, follicular cell damage and fibrosis (hematoxylin-eosin, $\times 250$ ).

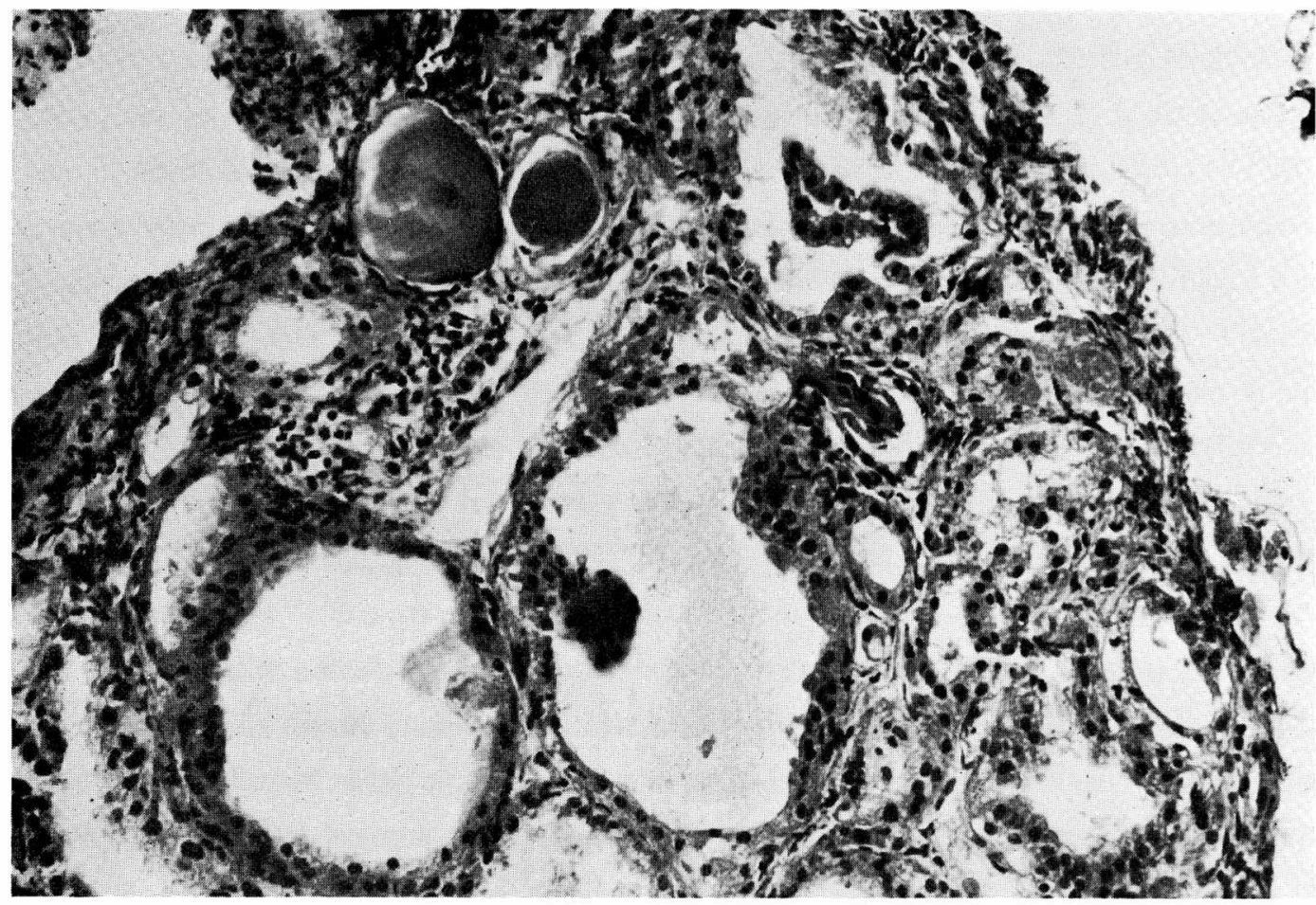

Fig. 1 B Thyroid biopsy specimen of Case 7 revealing papillary infolding of oxyphilic epithelium (hematoxylin-eosin, $\times 250$ ) 
the treatment was discontinued. However, she complained of palpitation with elevated $\mathrm{T}_{4}$ (20.4 $\mu \mathrm{g} / 100 \mathrm{ml})$ and $\mathrm{T}_{3}(460 \mathrm{ng} / 100 \mathrm{ml})$ in serum about 2 months after the treatment was discontinued. At this time, she also complained of thirst, polydipsia and polyuria, and glycosuria was found. The fasting blood sugar levels were markedly elevated (over $200 \mathrm{mg} / 100 \mathrm{ml}$ ) and not ameliorated following the treatment for thyrotoxicosis. The follow-up glucose tolerance test which was performed approximately 10 months after the first test showed frankly diabetic curve with markedly elevated fasting blood sugar level of $203 \mathrm{mg} / 100 \mathrm{ml}$ (Table 1). There was no responses of IRI to hyperglycemia (Table 1). She denied symptoms suggestive of viral infections during the course of the disease. The thyroid biopsy specimen obtained before the treatment with antithyroid drug showed lymphocytic infiltrations, follicular cell damage and fibrosis (Fig $1 \mathrm{~A})$. Moreover, as shown in Fig. 1 B, papillary infolding of oxyphilic epithelium was evident, suggesting the the overlapping of Graves's disease and Hashimoto's thyroiditis.

\section{Discussion}

It is well-known that abnormalities in glucose tolerance curves are often encountered in patients with Graves' disease. However, these abnormalities are usually mild, with normal fasting blood sugar levels, and are ameliorated following the improvement of thyrotoxicosis. Contrary to such mild glucose intolerance, 7 patients with Graves' disease described in the present paper had typical symptoms of overt diabetes, such as thirst, polyuria and polydipsia, and elevated fasting blood sugar levels. The glucose intolerance was not improved even after thyrotoxicosis was corrected and all patients required insulin therapy for the control of diabetes. Although ketosis was not always found in all cases, we considered that they had IDDM.

Previous studies have demonstrated that the prevalence of hyperthyroidism in IDDM was 3 $\%^{4)}$ or $5.2 \%^{3)}$. In the present study, 7 insulin dependent diabetics were found in 270 patients with Graves' disease and the prevalence $(2.6 \%)$ was almost comparable to that reported previously ${ }^{3}{ }^{4}$. It has been previously shown that the prevalence of hyper- and hypo-thyroidism is significantly greater in IDDM than in the general population ${ }^{4)}$. Moreover, recent study ${ }^{7)}$ showed the prevalence of subclinical primary thyroid failure, indicated by raised serum TSH levels, in IDDM to be approximately twice that reported in insulin-independent diabetics and non-diabetics. The increased prevalence of organspecific antibodies in serum including thyroid autoantibodies in patients with IDDM has been demonstrated by several investigators ${ }^{1,2,8)}$. Therefore, IDDM (Type I diabetes) can be divided into diabetes which may occur in response to hypothetical viruses (Type I a) and primary autoimmune diabetes (Type I b) ${ }^{1-4,9-12)}$. The latter form of IDDM is characterized by persistence of islet cell antibody in serum, coincident autoimmune disorders including Graves' disease and Addison's disease with overre- 
presentation of the same HLA antigen, female predominance, an older age of onset and strong family histories of diabetes mellitus, thyroid diseases and other autoimmune disorders ${ }^{1-4)}$. Moreover, in thyrotoxic patients with IDDM thyroid antimicrosomal antibodies are present in much higer proportion than uncomplicated thyrotoxicosis ${ }^{1},{ }^{2)}$. In the present parer all thyrotoxic patients with IDDM were women and the age of onset of diabetes was 30 years of age or later in 5 of 7 patients. The high titers of circulating antimicrosomal antibody in 5 cases, and family history of diabetes mellitus and goiter in 5 cases are also compatible with the autoimmune type of diabetes mellitus $\left.{ }^{1},{ }^{2},{ }^{12}, 13\right)$, although the data on islet cell antibody and HLA antigen were not available in these cases.

An interesting feature of the present study is histology of the thyroid specimen obtained in 3 cases. Typical parenchymatous hypertrophy characterizing Graves' disease was observed in addition to the follicular cell damage, interfollicular lymphocytic infiltration and fibrosis. Oxyphilic epithelial cells were present in cases 4 and 7, and its papillary infolding was seen in case 7. Although focal infiltrations of lymphocytes are often observed in the thyroid in Graves' disease, these are seldom extensive. Moreover, oxyphilic epithelium, follicularc ell damage and fibrosis were usually not observed in the thyroid of Graves' disease. Therefore, the histological findings obtained in the present study indicate that Hashimoto's thyroiditis coexists with Graves' disease. The hyperthyroid complication of Hashimoto's thyroiditis has been referred to "Hashitoxicosis" ${ }^{14)}$. Previous study ${ }^{15)}$ has described 24 thyrotoxic patients associated with histologic Hashimoto's thyroiditis. Their thyroid glands showed either histological feature of Hashimoto's thyroiditis alone or a mixture of both parenchymatous hypertrophy of Graves' disease and extensive lymphocytic infiltrations. Moreover, it is noteworthy that the high prevalence of diabetes mellitus or of family history of diabetes has been observed in these thyrotoxic patients with Hashimoto's thyroiditis ${ }^{15}$. Thus, the overlapping of Graves' disease and Hashimoto's thyroiditis may be a histological feature of the thyroid in thyrotoxic patients associated with diabetes mellitus, especially IDDM, although the histological examination of the thyroid were not done in all thyrotoxic patients associated with IDDM in the present study.

Recently, there have been several reports of thyrotoxicosis with low thyroid uptake of radioactive iodine and spontaneous remission after a short duration of thyrotoxic state ${ }^{14,16-19)}$. The histological findings of thyroid biopsy specimen in these patients were compatible with lymphocytic thyroiditis and parenchymatous hypertrophy was not evident ${ }^{14},{ }^{16-19}$ ). In contrast to the painless thyroiditis associated with transient thyrotoxicosis, the present patients had elevated thyroidal uptake of ${ }^{131} \mathrm{I}$ and more persistent thyrotoxicosis than that observed in patients with painless thyroiditis ${ }^{14}$, 16-19) $^{\text {. }}$

Glucose intolerance observed in Case 7 deserves discussion. The first glucose tolerance test 
performed during the thyrotoxic state revealed mild glucose intolerance associated with normal IRI response. Howwever, overt diabetes with elevated fasting blood sugar levels and absent IRI response to glucose was observed 10 months later with recurrence of thyrotoxic state. This might be explained by the diabetogenic action of thyroid hormone ${ }^{20)}$. However, the abrupt onset of insulinopenic diabetes and the coexistence of Graves' disease associated with Hashimoto's thyroiditis in this patient might suggest the primary autoimmune type of diabetes mellitus.

\section{Reference}

1) Bottazzo, G. F., Cudworth, A.G., Moul, D. J., Doniach, D. and Festenstein, H. : Evidence for a primary autoimmune type of diabetes mellitus. Br Med J 2, 1253, 1978.

2) Bottazzo, G. F., Mann, J. I., Thorogood, J.D. Baum and Doniach, D. : Autoimmunity in juvenile diabetics and their families. Br Med J 2, 165, 1978.

3) Gray, R. S. and Clarke, B. F. : Primary autoimmune diabetes mellitus. Br Med J 2, 1715, 1978.

4) Nabarro, J. D. N., Mustaff, B. E., Morris, D. V., Walport, M. J. and Kurtz, A. B. : Insulin deficient diabetes. Contrasts with other endocrine deficiencies. Diabetologia 16, 5, 1979.

5) Crile, G. Jr. and Vickery, A. L. : Special uses of the silverman biopsy needle in office practice and at operation. Am J Surg 83, 83, 1952.

6) Werner, S. C. : Classification of the eye changes of Graves' disease. J Clin Endocrinol Metab 29, 982, 1969.

7) Robert, S. G., Borsey, D. Q., Seth, J., Herd, R., Brown, N. S. and Clarke, B. F. : Prevalence of subclinical thyroid failure in insulin-dependent diabetes. J Clin Endocrinol ; Metab 50, 1034, 1980.

8) Nagaoka, K., Sakurami, T., Nabeya, N., Imura, H. and Kuno, S. : Thyroglobulin and microsomal antibodies in patients with insulin-dependent diabetes mellitus and their relatives. Endocrinol Japan 26, 213, 1979.

9) Irvine, W. J. : Classification of idiopathic diabetes. Lancet 1, 638, 1977.

10) National diabetes data group, NIH: Classification and diagnosis of diabetes mellitus and other categories of glucose intolerance. Diabetes 28, 1039, 1979.

11) Rotter, J. I. and Rimoin, D. L. : Heterogeneity ln diabetes mellitus — update 1978 : evidence for further genetic heterogeneity within juvenile-onset insulin-dependent diabetes mellitus. Diabetes 27, 599, 1978.

12) Cudworth, A.G. : Type I diabetes mellitus. Diabetologia 14, 281, 1978.

13) Irvine, W. J., Gray, R.S. and McCallum, C. J. : Pancreatic isletcell antibody as a narker for asymptomatic and latent diabetes and prediabetes. Lancet 2, 1097, 1976.

14) Woolf, P. D. : Transient painless thyroiditis with hyperthyroidism: A variant of lymphocytic thyroiditis? Endocrine Reviews 1, 411, 1980.

15) Fatourechi, V., McConahey, W. M. and Woolner, L. S. : Hyperthyroidism associated with histologic Hashimoto's thyroiditis. Mayo Clin Proc 46, 682, 1971.

16) Gluck, F. B., Nusynowitz, M. L. and Plymate, S. : Chronic lymphocytic thyroiditis, thyrotoxicosis, and low radioactive iodine uptake. N Eng J Med 293, 624, 1975.

17) Woolf, P. D. and Daly, R. : Thyrotoxicosis with painless thyroiditis. Am J Med 60, 73, 1976.

18) Inada, M., Nishikawa, M., Oishi, M., Kurata, S. and Imura, H. : Transient thyrotoxicosis associated with painless thyroiditis and low radioactive iodine uptake. Arch Intern Med 139, 597, 1979. 
$s-32$

19) Inada, M., Nishikawa, M., Naito, K., Ishii, H., Tanaka, K. and Imura, H. : Reversible changes of the histological abnormalities of the thyroid in patients with painless thyroiditis. J Clin Endocrinol Metab 52, 431, 1981.

20) Houssay, B. A. : Thyroid and metathyroid diabetes. Endocrinology 35, 158, 1944. 